\title{
O ESCRITOR INTERMEDIÁRIO: UMA NOVA ABORDAGEM DE UM TIPO DE ESCRITOR
}

\section{THE INTERMEDIATE WRITER: A NEW APPROACH OF A WRITER TYPE}

\section{LE SCRIPTEUR INTERMÉDIAIRE : UNE NOUVELLE APPROCHE D'UN TYPE DE SCRIPTEUR}

\author{
Elizabeth Villarreal ${ }^{*}$ \\ Freiderikos Valetopoulos ** \\ Tradução de Cynthia Pires Amaral ${ }^{* * *}$
}

\section{RESUMO}

Esta pesquisa tem como ponto de partida uma análise das necessidades de um público de estudantes universitários colombianos que desejam melhorar suas competências na escrita de textos acadêmicos. Propomos primeiramente analisar o processo de produção escrita apresentando um panorama de diferentes propostas teóricas. Após a análise, nos concentraremos na noção do "escritor intermediário", como uma etapa no processo do desenvolvimento da competência escrita. Trata-se então de um escritor que, contrariamente aos escritores novatos, pode articular, compreender e realizar tarefas bem estruturadas em nível de pensamento, o que revela a capacidade de transformá-las. Tais qualidades permitem situar o escritor no "modo de compreensão de conhecimento" devido às características que apresenta diante do processo de escrita. Nesse sentido, ele não deve ser considerado um escritor novato, pois tem a capacidade de ir além da simples enunciação de conhecimento, no entanto, não pode ser considerado um "escritor experiente", já que o seu trabalho de escrita não demonstra ainda a sua capacidade de transformação daqueles conhecimentos.

Palavras-chave: produção escrita, escritor novato, escritor intermediário, escritor experiente.

\section{ABSTRACT}

This research begins with an analysis of the needs of a population Colombian university student, who require the acquisition of academic text writing skills. We propose to analyze the written process by presenting an outline of different theoretical models. Furthermore, we will focus on the notion of the "intermediary writer" as a step in the development of written competence. The intermediate writer, unlike novice writers, can articulate, understand, and perform well-structured tasks at the cognitive level, which reveals its capacity to transform

\footnotetext{
* Universidad Libre da Colombia. Colombia. elizabeth.villarrealc@unilibrebog.edu.co

** Universidad de Poitiers. França. freiderikos.valetopoulos@univ-poitiers.fr

*** Universidade Estadual de Campinas, Campinas SP. Brasil. cynthiapa@gmail.com
} 
them. These qualities allow us to place this kind of writer in a "mode of understanding knowledge" due to the characteristics that it exhibits prior to the writing process. Thus, he should not be considered as a novice writer, since he has the capacity to go beyond the simple enunciation of knowledge, however, he can not be considered as an "experienced writer", since his capacity of writing to transform Knowledge.

Keywords: written production, beginner writer, intermediate writer, experienced writer.

\section{RÉSUMÉ}

Cette recherche trouve sa source dans une analyse des besoins d'un public d'étudiants universitaires colombiens qui souhaitent améliorer leurs compétences en rédaction de documents académiques. Nous nous proposons tout d'abord d'analyser le processus de production écrite en présentant un panorama des différentes propositions théoriques. Dans la suite de cette analyse, nous nous concentrerons sur la notion du « scripteur intermédiaire » comme une étape dans le processus du développement de la compétence écrite. Il s’agit alors d'un scripteur qui, contrairement aux scripteurs novices, il peut articuler, comprendre et réaliser des tâches bien structurées, au niveau de la pensée, ce qui révèle sa capacité à les transformer. Ces qualités permettent de les situer dans «le mode de compréhension des connaissances », en raison des caractéristiques présentées face au processus d cécriture. Dans ce sens, il ne peut pas être considéré comme un scripteur novice, car il est au-delà de la simple énonciation de la connaissance, mais comme un scripteur expert non plus, car son travail d`écriture ne démontre pas encore sa capacité pour transformer ces connaissances. Mots-clés: production écrite, scripteur novice, scripteur intermédiaire, scripteur expert

\section{INTRODUÇÃO}

O presente estudo tem como ponto de partida um trabalho de pesquisa de doutorado realizado pelo laboratório FoReLL EA 3816. Tal estudo concentrouse na análise das dificuldades em redigir textos acadêmicos encontradas por um grupo de estudantes da Universidade Libre da Colômbia. Essa pesquisa foi baseada em dois trabalhos preliminares realizados na Universidade Libre de Bogotá, na Colômbia. O primeiro tinha por objetivo a avaliação do nível de língua dos estudantes ao término de uma formação em Francês Língua Estrangeira (ACUÑA, MOYA \& VILLARREAL, 2008). O segundo trabalho colocou em evidência a falta de autonomia dos estudantes quando sentem a necessidade de apropriar-se de seu aprendizado, o que os impede de adquirir um domínio suficiente da língua estrangeira a fim de se tornarem falantes independentes (MORA \& MURCIA, 2009). Além disso, a falta de organização demonstrada pelos alunos em relação à maneira de gerenciar o tempo livre tem um impacto direto nos resultados de sua aprendizagem e no nível de língua alcançado.

Isso confirmou a necessidade de se colocar em prática um trabalho de pesquisa que pudesse elaborar uma metodologia destinada a desenvolver processos 
de aprendizagem que possam ajudar os estudantes a vencer suas lacunas e a melhorar suas competências comunicativas. Nesse contexto, preferimos continuar a refletir acerca de uma remediação das dificuldades encontradas pelos estudantes, com o desenvolvimento do Programa interativo para aprendizagem autônoma do Francês, denominado desde então PIAF (VILLAREAL, 2009). Essa ferramenta interativa permite que os estudantes possam melhorar suas competências comunicativas em Francês Língua Estrangeira (FLE) e desenvolver o trabalho em autonomia, com apoio de recursos para aprendizagem do FLE disponíveis na internet.

O dispositivo PIAF foi implementado na plataforma da Universidade Libre da Colômbia e, a partir do primeiro semestre de 2009, um projeto piloto começou com os estudantes de francês da Faculdade de Filosofia. Esses estudantes eram motivados por uma necessidade urgente de aprender a língua francesa para se beneficiarem do acordo de duplo-diploma com a Universidade de Poitiers.

Após dois anos de projeto piloto com os alunos da Faculdade de Filosofia, foi possível concluir que os estudantes progrediram em nível de aprendizagem autônoma e melhoraram a competência comunicativa em francês. Tudo isso se deve, em grande parte, à motivação gerada pela combinação de um estudo disciplinar com o aprendizado da língua. Valetopoulos e Lamprou (2008, p. 137) ressaltam uma situação parecida a respeito de estudantes cipriotas. Eles puderam constatar um grande nível de competências quando os estudantes trabalham no contexto de sua formação acadêmica, mas igualmente destacam as dificuldades em se expressarem quando são confrontados com assuntos que não possuem relação direta com seus estudos. Esse mesmo estudo revelou as dificuldades que os estudantes encontram em relação à proficiência da língua, à organização das estruturas dos textos acadêmicos e à falta de conhecimentos gramaticais e lexicais, elementos que os permitiriam construir corretamente uma argumentação.

Nesse contexto, os estudantes que constituíram o público de nossa nova pesquisa foi frequentemente confrontado com a preparação de textos acadêmicos, que exigem o domínio do processo de escrita. Contudo, eles não possuem forçosamente as competências necessárias para responderem, de maneira efetiva, a esse tipo de exigência. À primeira vista, as produções escritas nos permitem constatar a presença de repetições, uma falta de coerência e coesão ou mesmo uma argumentação inadequada. A tudo isso vem se juntar a dificuldade de escrever em uma língua estrangeira, o que confirma a necessidade de dominar uma metodologia que permita remediar todas as dificuldades mencionadas acima. 
Na sequência deste artigo nos concentraremos primeiramente nos diferentes critérios referentes à produção escrita e, na sequência, apresentaremos uma nova etapa, a do escritor intermediário.

\section{AS ETAPAS DO PROCESSO DE PRODUÇÃO ESCRITA}

Nesta parte do artigo apresentaremos um breve panorama dos diferentes modelos de produção escrita e suas relações com a didática das línguas, primeira língua ou língua estrangeira.

\subsection{0 modelo linear}

Começamos pelas contribuições do modelo de Rohman \& Wlecke (1964) e o de Rohman (1965), cujos estudos foram os que mais influenciaram o ensino da escrita. Esse modelo é conhecido por ser um modelo em etapas, pois estabeleceu um processo que compreende a pré-escrita, a escrita e a reescrita. Foi um modelo amplamente aceito na educação, pois dá ao escritor a possibilidade de avançar de maneira organizada e programada no processo de produção linear (CAMPS, 1990; NEIRA \& FERREIRA, 2011).

Cada uma dessas etapas é distinta porque todas exigem uma operação independente e, consequentemente, levam a resultados diferentes. A pré-escrita está centrada no planejamento (planning) e na busca de ideias que vão, finalmente, ajudar a desenvolver todo o trabalho de redação do texto. Ela vai levar à concretização da segunda etapa, a escrita, que diz respeito ao desenvolvimento organizado das ideias. A terceira etapa, a reescrita, dá lugar à releitura, para se voltar ao texto e fazer o trabalho de correções de forma e conteúdo.

Esse modelo tem uma forma unidirecional que deve ser respeitada de maneira estrita, o que torna difícil o trabalho de vai-e-vem nas ideias e no texto durante a escrita. Ele também pode funcionar com escritores que não possuem experiência, uma vez que o modelo demanda operações mentais básicas e não exige conexões muito complicadas (DEWAELE \& WOURM, 2002).

Centrado no produto final, "o texto" (CAMPS, 1990), esse modelo apresenta a desvantagem, se assim podemos dizer, de não levar em consideração as diferentes operações que permitem transformar e reutilizar os conhecimentos já adquiridos. Em outras palavras, esse modelo não permite realmente a ênfase nas estratégias metacognitivas do escritor: o tempo reservado para análise, planejamento e correção, etapas indispensáveis para se atingir a transformação do conhecimento adquirido. 
Além disso, Sommers (1978) ressalta que diferentes pesquisas mostraram que o escritor chega ao mesmo resultado, o texto, sem obrigatoriamente seguir a ordem preestabelecida.

Podemos, sem dúvida, constatar que o modelo linear é o ponto de partida que deu origem às várias teorias que contribuíram para a evolução do processo de escrita. Mas foi, ao mesmo tempo, um obstáculo em alguns países. Segundo Caldera (2003), o ensino da escrita foi uma das tarefas principais da escola. Nas últimas décadas, os esforços de alguns países da América latina, como Peru, Bolívia, Equador ou Colômbia, foram significativos para se atingir melhores resultados nas pesquisas em áreas como linguística, psicologia, educação, entre outras, que oferecem as principais chaves para o processo de escrita, práticas pedagógicas, assim como o conceito de ensino e aprendizagem. Apesar dos esforços, os resultados nesses países mostram que a maior parte dos estabelecimentos de ensino não chegam a abandonar a prática do modelo linear; fator que pode ter uma influência significativa nas dificuldades apresentadas pelos estudantes colombianos frente às exigências da escrita acadêmica, o que pode igualmente explicar os baixos resultados dos alunos nessa competência.

Além disso, Martinez e Zabala (2015) observam que esperamos de uma parte dos estudantes de nível superior que eles dominem as etapas desse processo, pois eles vêm de uma formação que lhes permite responder às exigências de produção de texto. A realidade é outra. Os estudantes que começam os estudos universitários apresentam dificuldades relativas à escrita e à leitura, que os impedem de expressar com clareza seus conhecimentos, o que leva um grande número de alunos ao fracasso, quando não, ao abandono.

\subsection{0 modelo não linear}

O modelo não linear se configurou como uma nova abordagem do processo de escrita. Hayes \& Flower (1980) e Bereiter \& Scardamalia (1987) elaboraram modelos que levam em conta as etapas propostas por Rohman. No entanto, apresentam uma maneira diferente de análise, em que as inter-relações cognitivas servem de apoio à escrita a partir de um procedimento recursivo integrado em três etapas: a planejamento, a tradução e a revisão. Além disso, Cassany (1989) propõe uma outra teoria recursiva próxima aos modelos anteriores. Essa teoria inclui a planejamento, a textualização e a revisão, que descrevem um conjunto de etapas que permitem a melhor compreensão do processo. Van Dijk \& Kintsch (1983) propõem, enfim, a planejamento, a organização e a realização, enquanto Salazar (2007) fala de concepção, produção e avaliação. Apesar 
de suas divergências, vários elementos parecem comuns entre todas essas teorias (Esquema 1).

Esquema 1. Algumas abordagens teóricas que representam o modelo não linear

\section{Processos de escrita}
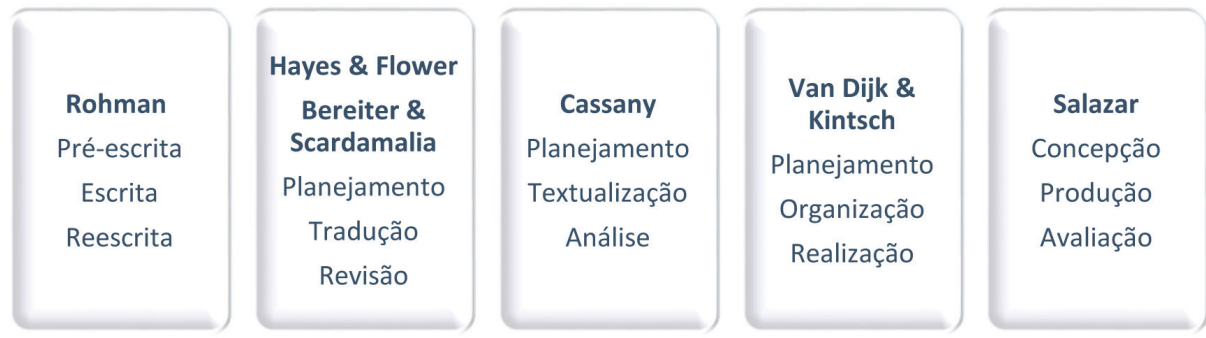

Não vamos nos propor à análise de todos esses modelos, mas nos deteremos em três teorias; as duas primeiras se concentram nas necessidades do público adulto (HAYES \& FLOWER, 1980; CASSANY, 1989), enquanto a terceira abordagem analisa o processo de escrita levando em consideração as competências que possuem os escritores treinados e não treinados (SCARDAMALIA \& BEREITER, 1982). Essas teorias nos fornecerão os elementos necessários para darmos sequência à nossa análise.

\subsubsection{Hayes \& Flower (1980): um modelo para o público adulto}

Hayes \& Flower (1980) propõem um modelo que compreende três elementos essenciais: 1) o contexto da tarefa, que integra diferentes fatores, tais como o ambiente, o sujeito ou os leitores, capazes de influenciar a atividade de escrita e seu resultado; 2) a memória a longo prazo, que contém os conhecimentos relativos aos diferentes sujeitos, aos leitores e aos esquemas de textos precisos; 3) o processo cognitivo de escrita, que é proposto com base nos processos de planejamento (planning), tradução (translating) e revisão (reviewing).

Esse modelo destaca a importância da reflexão e/ou do desenvolvimento de novas representações que partem de modelos existentes, pois torna possível a) a solução de problemas ou o desenvolvimento mental de uma sequência para atingir um objetivo; b) a tomada de decisão ou avaliação e escolha do caminho a seguir; e c) as conclusões ou desenvolvimento de novas informações levando em conta os 
modelos existentes. A reflexão como processo cognitivo adquire uma dimensão complexa, que pode ajudar a completar a formação dos estudantes em questão, pois está incorporada às operações cognitivas, tais quais: a planejamento, integrada por sua vez a três sub processos que são a recuperação, a avaliação e a organização das ideias; o processo de tradução (translating), que permite a seleção de elementos linguísticos da memória a longo prazo sob a supervisão do plano de redação com a finalidade de levar uma forma linguística às ideias; a revisão (reviewing), que permite melhorar, mudar de ideias e completar o texto, corrigir erros para melhorar a qualidade (ÁLVAREZ \& RAMIREZ, 2006).

A principal característica desse modelo é que não obriga uma organização definida; funciona de maneira recursiva de acordo com as exigências de apresentação do texto durante o processo de redação, o que permite um trabalho de vai-e-vem permanente nas diferentes etapas do processo, facilitando a correção na mesma prática do processo de escrita. Esses aspectos nos fornecem elementos preciosos que são indispensáveis para reforçar a formação e a aprendizagem dos estudantes, uma vez que facilitam a redação.

Hayes (1996), a fim de completar esse modelo, propõe que sejam consideradas duas dimensões:

1. A dimensão do ambiente da tarefa em relação ao destinatário e as contribuições de leitura de outros textos. Ele confere também uma importância aos meios de escrita e ao texto final.

2. Os quatro elementos que integram a dimensão do indivíduo: a motivação e as emoções, a memória de longo prazo e a memória de trabalho, bem como os processos cognitivos.

Embora o modelo de Hayes e Flower (1980) e Hayes (1996) forneçam os elementos necessários para a produção escrita, é importante, de acordo com nossa opinião, apresentar igualmente a teoria de Cassany (1989), que traz novos elementos capazes de completar os outros modelos.

\subsubsection{A teoria de Cassany (1989)}

Essa teoria é próxima do modelo de Hayes \& Flower (1980), principalmente da última versão proposta por Hayes (1996). Cassany se baseia nas quatro abordagens expostas por Shih (1986) no que se refere ao ensino da escrita: a abordagem gramatical, a abordagem funcional, a abordagem baseada no processo e a abordagem baseada no conteúdo. Mais precisamente, ele se interessa mais pela 
abordagem baseada no processo, que considera que os conhecimentos gramaticais e o bom uso da língua não são suficientes para se ter um bom nível de escrita. É também indispensável o domínio de outras estratégias como a elaboração de esquemas, a revisão, a correção ou reformulação.

O conjunto de todas essas habilidades constitui o perfil do escritor competente, que leva em conta seu leitor. Ele escreve rascunhos, revisa suas ideias, trabalha na reestruturação do texto, usa uma linguagem compreensível para o leitor e se volta para o texto a fim de mudar, completar ou corrigir suas ideias. Todas essas qualidades são reiteradas por Cassany, Luna \& Sanz (2007, p. 262), que destacam, também, que um escritor competente é aquele que leva em consideração seu leitor, escreve projetos, desenvolve ideias, examina-as, revisa o contorno do texto e busca uma linguagem comum para se expressar com seu leitor. Por outro lado, Cassany (1989) indica que um bom processo de composição é caracterizado pelos seguintes fatores:

a) Tomar consciência das características dos leitores: é importante que o escritor reflita, por exemplo, sobre o que ele quer dizer aos leitores, sobre o que eles sabem e como deseja se apresentar.

b) Planejar o texto: antes da elaboração de um texto, é necessário planejá-lo ou estruturá-lo. Assim, o autor terá um esquema mental do texto que será escrito.

c) Reler as partes redigidas: enquanto a escrita avança, o autor relê as partes redigidas para certificar-se da coerência e do desenvolvimento do texto.

d) Revisar o texto: enquanto escreve e relê as partes do texto, o autor revisa e faz as modificações necessárias. Modificações que afetam principalmente o conteúdo do texto.

Durante a composição, o autor utiliza igualmente estratégias de apoio para resolver certos imprevistos que podem ocorrer, como, por exemplo, consultar uma gramática ou um dicionário, utilizar suas competências adquiridas para fazer esquemas ou resumir outros textos, identificar as informações pertinentes e, em seguida, transformá-las em resumos analíticos e sintéticos.

Desse modo, Cassany (1989) se adapta ao modelo cognitivo de elaboração de textos que está na mesma orientação do proposto por Hayes \& Flower (1980). Por outro lado, a abordagem baseada nos processos, proposta por Cassany, evidencia o escritor e não o texto escrito. O importante não é o resultado final, mas as etapas a serem seguidas para a obtenção do resultado.

Mas partindo das produções de nossos próprios alunos, podemos nos perguntar sobre o estatuto de escritor competente dos estudantes, e, mais 
precisamente, dos estudantes colombianos. Como já foi destacado (VILLARREAL, 2016), esses estudantes cometem erros de repetição, de fuga ao tema, suas produções apresentam falta de lógica, uma argumentação fraca e, com frequência, ignoram as regras relativas à estrutura dos textos. Acrescente-se a tudo isso a dificuldade de escrita em língua estrangeira, aumentando um grau de complexidade. Em outras palavras, os escritores colombianos não possuem os conhecimentos necessários que lhes permitam determinar os elementos que compõem o processo de escrita. Dessa forma, eles seriam escritores novatos, como sugere o modelo de Scardamalia \& Bereiter (1992), que nos propomos a apresentar na sequência do artigo.

\subsubsection{0 modelo de Scardamalia e Bereiter (1982)}

Scardamalia \& Bereiter $(1982,1987)$ propõem um modelo que comporta quatro etapas: a planejamento, a contextualização, a revisão e a edição. Essas etapas estão associadas a certos aspectos cognitivos e metacognitivos:

a) $\mathrm{O}$ conhecimento do processo ou o conceito de escrita, em que o escritor identifica a complexidade e compreende o engajamento que a produção de um texto escrito demanda;

b) $\mathrm{O}$ conhecimento e a reflexão acerca da estrutura textual ou reconhecimento das condições textuais que permitem a coesão e a coerência;

c) O processo metacognitivo que leva em conta: 1) o conhecimento de suas próprias capacidades e autorregulação; e 2) a atitude diante da tarefa ou do processo de produção de um texto escrito.

Esse modelo contribuiu de maneira importante, pois se concentra na descrição do comportamento dos adultos enquanto escritores. Chamado de "Knowledgetransforming model", o que Cornaire \& Raymond (1999) traduzem por "modelo de transformação de conhecimento", esse modelo mostra a estratégia de um escritor capaz de adaptar suas ações cognitivas à identificação de suas dificuldades e de sua correção. Ele não se limita à informação que está em sua memória de longo prazo, mas busca outros recursos capazes de melhorar os resultados de sua tarefa final. Ele tenta melhorar forma e conteúdo do seu plano, bem como as interações entre escritor, leitor e texto, fazendo revisões frequentes e organizando seu trabalho para obter uma melhor recepção por parte do seu leitor.

O segundo ponto que nos parece importante é a análise do trabalho que os escritores novatos e escritores experientes realizam como duas atividades opostas que se baseiam em diferentes estratégias a fim de efetuar a produção escrita. 
Ao mesmo tempo, esse modelo determina as características dos escritores sem experiência, especialmente as crianças, e dos escritores que se tornam experientes, em especial os adultos. Essa abordagem permitiu precisar as necessidades do público de nossa pesquisa, considerando que os estudantes não possuem experiência, mas possuem todas as competências cognitivas que lhes permitem escrever.

No que diz respeito a essa situação, o modelo de Scardamalia \& Bereiter (1992) afirma que o processo de escrita não pode ser um modelo único de processo, mas que é necessário levar em conta diferentes modelos que propõem diferentes estágios de desenvolvimento de competências. Os autores argumentam que o processo utilizado por um jovem estudante e um escritor maduro não pode ser o mesmo.

A primeira estratégia proposta por Bereiter \& Scardamalia (1987) consiste no modelo de enunciação dos conhecimentos. Ela se destina aos escritores novatos, que recuperam informações a partir de uma tarefa (o assunto, o gênero e certos termos ou elementos lexicais da tarefa); eles restringem o trabalho de escrita ao tema e concentram-se na escrita do que sabem sobre o tema. Dessa maneira, seus textos refletem a organização de seus pensamentos e a ordem das ideias que possuem na memória, em virtude disso, usam o enunciado como única fonte de resgate de ideias. Se a informação recuperada é útil para o desenvolvimento do assunto, tornase uma produção escrita. Um dos inconvenientes desse processo é que os escritores não levam em conta o leitor alvo do texto (HAYES \& FLOWER, 1986; BEREITER \& SCARDAMALIA, 1987; CASSANY, LUNA \& SANZ, 2007).

Os autores declaram, no que diz respeito a essa estratégia, que os escritores novatos não possuem objetivos ou interesses claros no momento da escrita. Eles afirmam simplesmente que o sistema de execução desses escritores não possui recursos para introduzir, de maneira ativa, esses objetivos ou interesses no processo de composição.

A partir dessa afirmação, contudo, seria possível pensar que toda solução ao problema de geração de um discurso escrito por escritores novatos seria implicar menos conhecimento e economizar esforços mentais. Nesse caso, economizar esforços mentais significa tratar apenas alguns aspectos que a tarefa exige, reduzindo os procedimentos a simples rotina, a fim de evitar a análise necessária para atingir o objetivo.

Isso significa que os novatos possuem uma tendência à simplicidade e, por essa razão, não constroem textos embasados na reflexão e na observação dos aspectos contextuais à questão levantada. Por causa dessa facilidade, limitam o início do texto a um acontecimento, restringem-no a um momento, impedem 
sua planejamento e a possibilidade de enriquecê-lo ou de estabelecer as relações descritas acima. Contudo, não devemos esquecer que os escritores novatos analisados pelos autores são crianças, o que implica dizer que eles não possuem necessariamente as competências que permitem estabelecer processos mentais que levariam a desenvolver esse trabalho. Portanto, os escritores adultos que apresentam esse comportamento diante do processo de escrita demonstram claramente que não estão sendo expostos a esses tipos de exercícios acadêmicos.

Por outro lado, a segunda estratégia, que diz respeito ao modo de transformação dos conhecimentos, representa o processo ao qual o escritor experiente é confrontado quando levado a resolver um problema de escrita. Ele realiza o processo de maneira consciente, o que lhe permite passar do espaço do conteúdo do problema (o que eu acho?), no qual ele organiza seus conhecimentos referenciais, ao espaço do problema retórico (o que vou dizer?), que lhe permite determinar o objetivo geral e a estrutura do texto. Nesse modelo, a tarefa de escrita implica uma análise do problema e dos objetivos a serem atingidos (GALBRAITH, 2009). No que diz respeito a essa estratégia, é possível afirmar que o público de nossa pesquisa possui a capacidade de realizar o processo de maneira consciente, para passar à análise do conteúdo do problema, mas há dificuldades para organizar sua opinião, o que não permite bons resultados no momento de organizar as ideias e estruturar o texto.

\section{RUMO A UMA OUTRA VISÃO DO ESCRITOR DIANTE DESSE PROCESSO}

Embora a análise de Scardamalia \& Bereiter leve em consideração os dois tipos extremos de escritor, é sem dúvida necessário se perguntar como acontece todo o processo de correção quando se depara com escritores "novatos", mas que possuem todas as competências cognitivas que lhes permitam redigir sem que sejam capazes de estruturar suas ideias e se situarem, no fim das contas, no nível de um escritor experiente. Seria então viável sugerir o modo intermediário para um escritor que apresentasse características distintas dos outros dois tipos de escritores? Seria possível incluir, em outras palavras, o público de nossa pesquisa nesse modo - primeiramente por causa das deficiências estruturais do modelo educacional colombiano e, em seguida, por causa de outras dificuldades pessoais que se somam -, quando os escritores de nosso estudo escrevem em uma língua estrangeira?

Não nos esqueçamos do que foi observado por Torrance (1998) com relação à produção de textos argumentativos de nível universitário. Ele destaca que no momento da redação do texto, os estudantes não aprofundam a busca de ideias, 
mas utilizam indicadores retóricos somente para organizar o conteúdo e não para produzir um novo conteúdo.

Todos esses elementos nos levam a propor uma estratégia de interação, o modo de compreensão de conbecimentos, que representa os processos que os estudantes devem adquirir. Optamos por denominar esses estudantes escritores intermediários, pois são adultos, mentalmente maduros, mas a ausência de uma exposição à produção de texto impede-os de transformar o conhecimento pré-existente.

Dessa maneira, propomos um processo de escrita que visa gerar novos conhecimentos que respondam a necessidades dos estudantes de nossa pesquisa e a melhorar os resultados desses escritores, pela elaboração, compreensão, aprendizagem, transformação, e pela adoção de um sistema de aperfeiçoamento da escrita (ver Esquema 2).

O esquema abaixo recupera as ideias de Bereiter \& Scardamalia em relação à reconstrução da estrutura cognitiva do escritor e integra a estratégia do modo de compreensão de conhecimentos como fator que permitirá ao escritor intermediário passar do modo de enunciação de conhecimentos ao modo da compreensão, a fim de transformá-los. Na verdade, é necessário que ele seja levado em consideração para completar o processo de composição escrita.

Esquema 2. Processo de composição escrita a partir da reconstrução da estrutura cognitiva (VILLARREAL, 2016, p. 59)

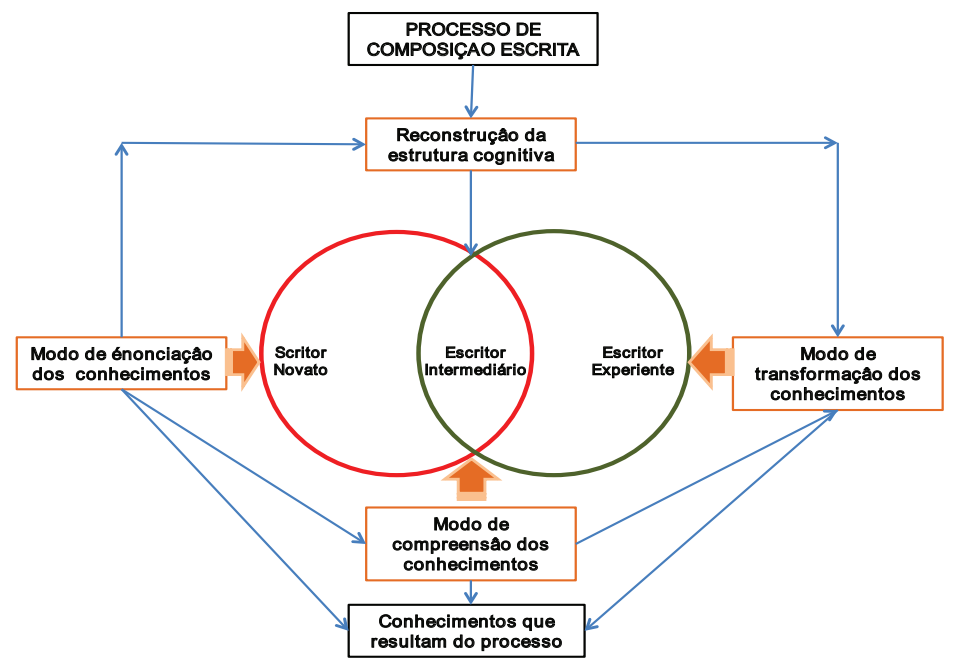


Como já levantamos mais acima, os escritores intermediários são estudantes que possuem características peculiares: são adultos, possuem maturidade mental, têm capacidade de estabelecer relações, mas, por outro lado, não dominam o processo de escrita e não conhecem todas as etapas que o compõem. Além disso, não receberam um treinamento necessário para sua compreensão. No entanto, são obrigados a produzir textos acadêmicos que exigem formação disciplinar. Nessas condições, são frequentemente obrigados a desenvolver os trabalhos de maneira intuitiva e a aprender a redigir a partir da prática quotidiana.

Essa situação obriga o escritor intermediário a reforçar o desenvolvimento de três etapas, expostas abaixo, que são indispensáveis para atingir o nível de um escritor experiente:

- Tomar consciência: conhecer as etapas que compõem o processo de escrita e compreender a necessidade de segui-las para se obter bons resultados.

- Treinar: seguir uma metodologia que facilite o treinamento de exercícios mentais, seguindo as exigências de cada etapa e guardando a ordem exata, a fim de compreender os elementos que o compõem.

- Colocar em prática: depois de ter entendido e aprendido como o processo se desenvolve, o escritor deve começar a preparar exercícios de escrita, colocando em prática cada uma das etapas exigidas.

Assim, os estudantes devem estar conscientes de que apenas a prática frequente e rigorosa pode permitir o domínio do processo de escrita e o alcance do nível de escritor experiente.

Também é importante analisar os modos do esquema 2 como partes que compõem um processo de formação por etapas. (Esquema 3 ). 
Esquema 3. Processo de formação por etapas.

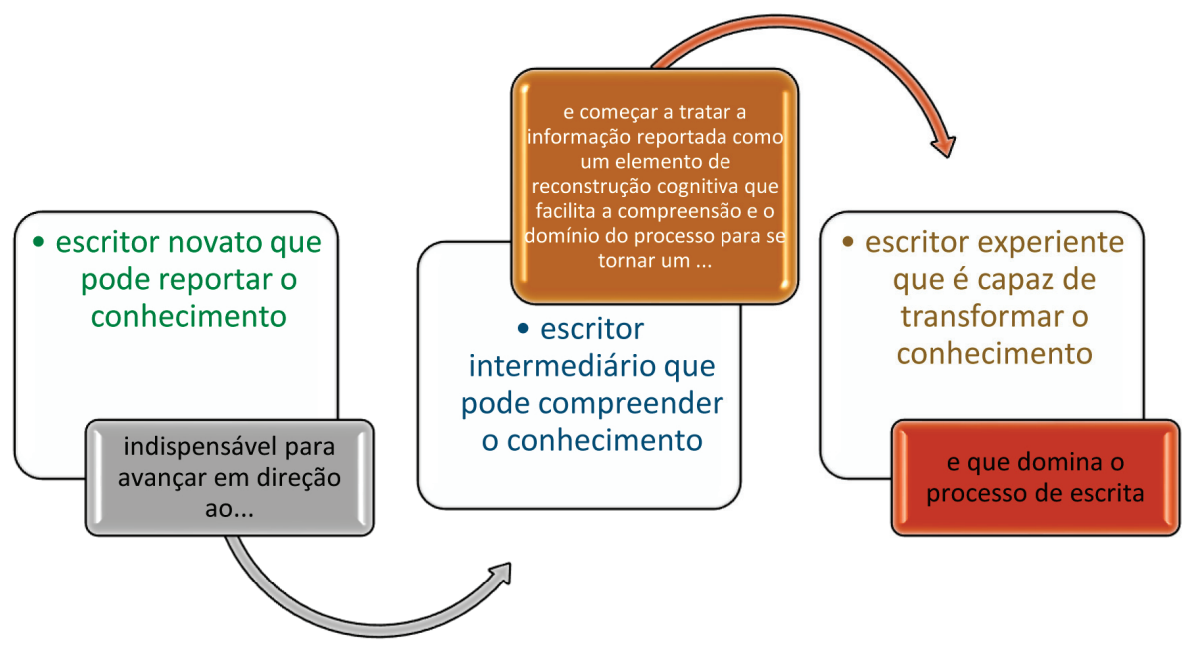

O esquema 3 exposto acima mostra que existem outros aspectos complementares, que participam do processo de escrita mencionado. Nesse sentido, levamos em consideração o que expõe De Beaugrande (1984) em relação ao processo de composição escrita. Ele apresenta a hipótese da representação mental das ideias principais, que desempenham um papel importante na produção de um texto. Ele chama de ideias, "pontos principais", as propostas centrais em torno das quais o texto se organiza e que outras propostas tentam sustentar. Sob o ângulo do processo de composição, o importante não é a maneira como os principais pontos estão apresentados no texto, mas a maneira como mostram a disposição do escritor.

Assim, o autor conclui que é o conjunto do processo de composição escrita que os escritores devem desenvolver, e não apenas um aspecto ou apenas uma das partes constitutivas. Dessa maneira, De Beaugrande confere uma atenção particular à melhora da composição, afirmando que a busca das representações mentais facilita o desenvolvimento do processo de composição, em direção aos níveis mais elevados. $\mathrm{O}$ que confirma, aliás, a importância de tratar a informação relatada como elemento de reconstrução cognitiva que facilita a compreensão, o que é proposto pelo processo de escrita por etapas apresentado acima.

Em todo caso, assim como De Beaugrande, outros modelos sugerem que o ensino da produção escrita deveria se concentrar em torno da ajuda que se pode dar aos estudantes, permitindo-lhes construir representações mentais que integram intenções e objetivos exigidos pelo processo de produção textual. Assim, os 
estudantes podem resolver problemas de conteúdo e construção retórica, a fim de promoverem a transformação do conhecimento. Ou seja, é necessário propor a busca sistemática de estratégias de controle para ajudar a reconstrução da estrutura cognitiva do estudante (ALVAREZ \& RAMIREZ, 2006).

A análise dos três modelos examinados acima nos leva a refletir sobre a importância da compreensão dos diferentes textos que podem ser produzidos pelos estudantes de acordo com sua idade e seu nível de maturidade enquanto escritores. Assim, é possível que, de fato, os escritores novatos (não maduros) possam obter resultados que estejam além da enunciação do conhecimento, e que possam passo a passo avançar em direção à redação de textos cada vez mais elaborados. Ou seja, nossa tarefa consiste em encontrar estratégias de produção textual que permitam aos escritores intermediários (novatos-maduros) atingir um nível de produção correspondente ao modo do escritor experiente.

\subsection{As Atividades de escrita que participam da reconstrução cognitiva}

Baseado no que foi dito anteriormente, Didactext (2006) apresenta a possibilidade de indicar atividades gerais, necessárias à produção de um texto escrito, a partir das quais pode-se criar estratégias didáticas que conduzam à reconstrução da estrutura cognitiva dos estudantes afim de facilitar o processo de preparação e desenvolvimento de textos:

1. O escritor recorre a seu saber e determina o tipo de texto. Ele procura a pista dos conhecimentos prévios sobre o texto a ser escrito.

2. Planeja a estrutura do texto. Ao fazer isto, ele seleciona ideias, estabelece o esquema do texto, considera os potenciais leitores, analisa a intenção e reflete sobre a contextualização do texto (recepção, caráter formativo, caráter situado e intertextualidade).

3. Produz ou constrói o texto. Para isso, escreve e organiza as ideias, concebe os parágrafos, hierarquiza as ideias, leva em conta as regras de produção textual e o modelo do texto, escreve um rascunho, decide sobre a utilização de gráficos, diagramas e outros recursos gráficos.

4. Examina o texto. Identifica os erros no que diz respeito a coerência, coesão e a recepção; dissipa as dúvidas; confirma a intenção e o objetivo esperado; identifica a pertinência dos títulos, subtítulos, gráficos, diagramas, etc., e aplica os guias de controle que permitem avaliar o texto.

5. Modifica o texto adequando sua estrutura. 
A partir da realização dessas atividades, o escritor deve se ocupar da realização da tarefa de escrita, tendo em conta as etapas que o processo exige.

\subsection{A Realização do processo de escrita}

Para melhor responder às necessidades de escrita dos estudantes e a fim de determinar as estratégias de produção intermediárias que permitirão melhorar a redação de textos acadêmicos, é indispensável analisar mais detalhadamente as três etapas do processo descritas, entre outros, por Hayes \& Flower (1980), Flower (1985), Bereiter \& Scardamalia (1987) e Cassany (1989). Trata-se da planejamento, da tradução e da revisão, três sub-processos que podem ser utilizados de maneira cíclica durante a redação, e que vão facilitar o percurso que leva a um processo mais eficaz. Comecemos pela análise do processo de planejamento e dos elementos que o integram, levando em conta o fato de que é um dos processos que apresenta mais dificuldade para escritores intermediários por causa das exigências do processo de análise.

\subsubsection{A Planejamento}

Nesta etapa o escritor planeja os objetivos que busca atingir, gera ideias, recupera e organiza os dados da memória a longo prazo (MLP). Ou seja, a planejamento do texto é entendida como uma estratégia que visa realizar ações propostas para um objetivo. O texto deve estar adaptado à situação e deve ser tratado como uma progressão de níveis, conhecimentos intelectuais, emocionais e sociais, etc. A planejamento deve ser favorável em relação ao objeto de escrita, às fontes e materiais, com ações e eventos, que permitam a resolução de problemas. Ela compreende os graus de motivação e de decisão para a preparação do texto.

Esses graus incluem três componentes que facilitam a planejamento a partir da análise do tema, do objetivo e da redação, com a intenção de informar e convencer (CACCAMISE, 1987). Trata-se da recuperação, da produção (generating), da seleção (organizing) e da avaliação das ideias. A primeira exerce uma função essencial dentro do processo, definindo o plano de redação em função da informação fornecida pela memória a longo prazo e do que obtemos a partir da tarefa a ser executada.

a) A Recuperação das ideias

As ideias estão armazenadas na memória a longo prazo. De acordo com Gaonac'h \& Larigauderie (2000, p. 48), o que torna possível a recuperação da memória a longo prazo é a interação entre os indícios oriundos do ambiente cognitivo 
do sujeito e um plano de recuperação estabelecido na memória, proveniente do tratamento efetuado ao longo do aprendizado. O sujeito desenvolve a memória a longo prazo ao longo de diferentes aprendizados. Sua função é armazenar definitivamente as informações adquiridas, assim como recuperar as informações estocadas que não são tratadas diretamente, ao contrário do que acontece com a informação proveniente da memória a curto prazo. Assim, se nos concentrarmos na produção, é importante ativar rapidamente as informações que temos na memória a longo prazo (ANDERSON, 1982). A ativação dessa informação é por vezes afetada pelas dificuldades encontradas no momento de lembrar do tema de maneira detalhada. Dessa forma, quando uma pessoa tenta se lembrar de informações precisas que foram armazenadas, ela se apoia na criação de um ambiente que a ajuda a se lembrar. Há um risco de perder uma parte da informação ao longo do processo de recuperação na memória a longo prazo.

De acordo com Baddeley (1990), não é possível recuperar todas as informações situadas na memória a longo prazo; para conseguir, é indispensável conhecer o acesso que facilita sua recuperação e sua disponibilidade, o que nos leva a verificar se elas estão estocadas na memória a longo prazo. Além disso, Denhiere \& Baude (1989) observam que a ativação dos conceitos semânticos dentro da memória a longo prazo é colocada em prática graças à construção de um indício de recuperação que permite dar sentido às informações selecionadas pela memória.

Ainda resta uma dúvida a respeito da informação armazenada dentro da memória a longo prazo. Ela contribui para a construção de argumentos ou ela é simplesmente um elemento que tem valor apenas na medida em que o escritor é capaz de tomar uma posição sobre a questão a ser abordada? $\mathrm{O}$ escritor deve aprofundar seus conhecimentos e conhecer o tema de maneira que possa ativar também a informação necessária que possui dentro da memória a curto prazo ou memória de trabalho - e que permite dar valor argumentativo à informação armazenada na memória a longo prazo, favorecendo assim a construção de bons argumentos.

b) A produção de ideias no exercício de escrita

Nesse processo, as ideias que temos na memória podem ser recuperadas em três etapas. A primeira é identificada logo após a utilização de uma sonda memorial (RAAIJMAKERS \& SHIFFRIN, 1981) que ativa a primeira informação e continua a recuperar as seguintes, produzindo uma reação em cadeia de associação de elementos. As duas outras etapas permitem avaliar a informação recuperada para traduzi-la em palavras no momento da redação ou conservá-la na memória 
de trabalho para ser utilizada de outra maneira durante o processo de escrita (BEREITER \& SCARDAMALIA, 1987; HAYES \& FLOWER, 1980).

O processo anteriormente descrito é conhecido pelo nome de generating (HAYES \& FLOWER, 1980). Embora ele permita a recuperação de ideias da memória a longo prazo, é preciso trabalhar na reorganização e reestruturação da informação, de acordo com seu nível de importância, levando em conta o destinatário e o nível da produção, o que obriga a modificar a ordem pela qual as ideias são recuperadas (FAYOL, 1991). Um outro fator que intervém é a maneira como as ideias se organizam dentro do processo; essa atividade vai dar apoio à planejamento através de uma boa seleção da informação.

c) Seleção e avaliação das ideias

Esse processo permite organizar as ideias. Ele se desenvolve segundo o princípio das relações semânticas prévias que as une; permite ao mesmo tempo a criação de outras relações entre elas no momento da recuperação (seleção da informação apropriada) ou da organização do plano que vai permitir a definição do conteúdo do texto.

Como reconhecem Flower \& Hayes (1980), o bom senso e a eficácia na pesquisa levam os escritores a evoluírem constantemente seus planos (escrevem e reescrevem) durante a redação do texto, sem que seja através de etapas facilmente identificáveis. Isso evidencia o conceito de escrita como processo (e não apenas como produto), e leva a uma melhor maneira de compreender o processo de escrita, que consiste em compreender um escritor enquanto ele escreve.

\subsubsection{A Textualização}

Nessa etapa, segundo Flower \& Hayes (1980), o escritor retorna às pistas detectadas durante a etapa anterior. Ele recupera o conteúdo semântico armazenado na memória a longo prazo, despeja-o na memória de trabalho, prepara um possível arranjo verbal para expressar o conteúdo, avalia essa forma e, se ela convém, redige-a levando em conta as regras linguísticas, retóricas e pragmáticas.

Dessa forma, Scardamalia \& Bereiter (1992) afirmam que na etapa de textualização é necessário se colocar várias questões: quais são as características do texto, quais são os elementos de argumentação que o compõem, e em que ordem ou em que hierarquia eles devem ser inseridos? É preciso também se perguntar sobre os fatores afetivos e os posicionamentos que serão refletidos no texto. Esses fatores se manifestam com a ajuda de vários elementos como: a modalidade (é obvio, é claro, 
certamente, etc.); a atitude (que é preferível, infelizmente, obviamente, etc.); a relação (considera-se, encontra-se aí, etc.); e a pessoa (é possível que os dados nos mostrem).

A esse respeito é preciso citar o que determina Díaz (2011). Ele afirma que "a coesão e a coerência são duas maneiras diferentes, mas estreitamente ligadas, que existem para poder apreciar duas estruturas de um texto: a interna e a externa". A interna é composta de modos e formas gramaticais utilizadas na construção de frases e permitem atingir a estrutura externa que o texto deve ter. Dessa maneira, pode-se dizer que não é possível progredir num processo de textualização sem respeitar a coerência e sem aplicar corretamente os mecanismos de coesão.

\subsubsection{A Revisão}

Nesta etapa o escritor reconhece três níveis: i) o controle da estrutura ou esquema da tarefa, ii) os processos fundamentais de interpretação, reflexão e produção; e iii) os recursos ou a memória de trabalho e de longo prazo. $\mathrm{O}$ escritor proficiente ou experiente revê constantemente o processo de produção e o produto. Consequentemente, um modelo preciso, como apresentado por Hayes \& Flower (1980), deve reconhecer os processos de base das reflexões que integram a planejamento e a análise.

Nessa perspectiva Bereiter \& Scardamalia (1987) mostram que, na fase de revisão, é comum fazer a seguinte pergunta: o que se diz está bem argumentado e bem expressado? Os argumentos são claros e de acordo com que critérios? Como dizer ou melhor argumentar para convencer seu destinatário? O que é preciso modificar, substituir, omitir ou acrescentar para atingir o objetivo? Que gráficos ou diagramas permitiriam reforçar o texto?

Hayes (1996) destaca a leitura como um instrumento que permite a revisão do texto. A tarefa de revisão não consiste apenas em ler para extrair o sentido do texto, mas permite também identificar os problemas e suas realizações. A tarefa de revisão é entendida como uma possibilidade de construção da leitura na qual se produzem operações de reinterpretação, de reflexão e de produção textual que compreendem o aperfeiçoamento do texto ou sua edição, a resolução dos problemas, a produção textual em que se observa a ilustração do tema de discussão, a representação da imagem do escritor e a representação do texto como um desdobramento espacial. A edição, enquanto fase final do processo, representa a satisfação do escritor e a do leitor em potencial.

O processo em questão implica a distinção das finalidades, tais quais: a leitura para compreensão, a leitura para definir o objetivo da tarefa e a leitura para 
análise final. As qualidades do escritor dependem de suas capacidades para exercer diferentes funções de leitura (ZETILI, 2010).

As observações acima são consideradas por muitos como constituintes de um trabalho de preparação a ser feito antes de se começar a escrita de um texto, seja ele qual for. O trabalho de análise anterior é uma exigência indispensável em todo processo de escrita. Analisar é o que permite ter a clareza e a profundidade necessárias sobre o assunto a tratar. Definir, organizar e hierarquizar os argumentos que sustentarão as ideias não é uma tarefa fácil. Isso demanda realizar um exercício completo que permita verificar outras fontes, estabelecer comparações e fazer um trabalho de seleção de ideias para examinar aspectos gerais e específicos que constituem o tema a ser desenvolvido (ZETILI, 2010).

\section{CONCLUSÃO}

Embora haja um grande número de autores que abordam a problemática da redação e as implicações que dela resultam, as perspectivas pedagógicas e os diferentes modelos de produção escrita propostos por Flower \& Hayes (1980), Cassany (1989) e Scardamalia \& Bereiter (1982) não abordam de maneira precisa as eventuais soluções que permitem resolver as dificuldades apresentadas pelo público da nossa pesquisa. Por essa razão, analisamos de maneira minuciosa as características dos escritores colombianos a fim de estabelecer os elementos que podem levá-los a superar suas dificuldades.

Dessa forma, chegamos à conclusão de que esses estudantes são escritores em nível intermediário, em relação ao processo de escrita, porque são adultos, mas as competências em produção escrita não possuem a mesma maturidade que lhes permitiria serem considerados escritores experientes (SCARDAMALIA \& BEREITER, 1982) ou competentes (CASSANY, 1989). Ou seja, os resultados desse trabalho de escrita não refletem a organização, o aprofundamento, a argumentação e a lógica que um trabalho bem escrito deve apresentar. Embora esses estudantes apresentem um nível de compreensão e apresentação, a falta de coesão e coerência ainda persiste, não permitindo confirmar suas competências em nível de processos mentais (VILLARREAL, 2016, p. 306).

Tendo definido as características do público, fica claro que eles apresentam uma fraqueza em relação ao nível de processos mentais. Tal situação nos leva a situá-los em um nível "intermediário" em relação aos escritores novatos por causa da facilidade em produzir textos escritos e de sua maturidade em relação ao pensamento. Assim, os alunos colombianos seriam colocados preferencialmente na etapa intermediária, pois seu trabalho de redação vai além da simples enunciação de 
conhecimento (escritor novato), mas não sabem transformar esse conhecimento. Desta forma, o modo de compreensão de conhecimento define claramente as necessidades que possuem diante da produção escrita. E o ensino da competência escrita deveria ir, portanto, nesse sentido.

\section{REFERÊNCIAS BIBLIOGRÁFICAS}

ACUÑNA, F., MOYA, S., \& VILLARREAL, E. (2007). Diagnóstico del nivel de competencias comunicativas en Francés de la Universidad Libre de Bogotá. Bogotá: Universidad Libre de Colombia.

ÁlVAREZ ANGULO, T., \& RAMíREZ BRAVO, R. (2006). Teorías o modelos de producción de textos en la enseñanza y el aprendizaje de la escritura. Didáctica (Lengua y Literatura), 18, 29-60.

ANDERSON, R. (1982). Acquisition of cognitive skills. Psychological Review (89).

BADDELEY, A. (1990). Human Memory: Theory and Practice. London: Lawrence Erlbaum Associates.

BEREITER, C., \& SCARDAMALIA, M. (1983). Does learning to write have to be so difficult? In A. Freedman, I. Pringle, \& J. Yalden (Edits.), Learning to write: First Language / Second Language. Longman.

BEREITER, C., \& SCARDAMALIA, M. (1987). The Psychology of Written Composition. Hillsdale, N.J.: Lawrence Erlbaum.

CACCAMISE, D. J. (1987). Idea generation in writing. In A. Matsuhashi (Ed.), Writing in real time: modeling production processes (p. 224-253). Norwood, NJ: Ablex.

CALDERA, R. (2003). El enfoque cognitivo de la escritura y sus consecuencias metodológicas en la escuela. EDUCERE, ARTíCULOS(20), 363-368.

CAMPS, A. (1990). Modelos del proceso de redacción: algunas implicaciones para la enseñanza. Infancia y Aprendizaje, 49, 3-19.

CASSANY, D. (1989). Describir el escribir, cómo se aprende a escribir. Barcelona: Paidós.

CASSANY, D., LUNA, M., \& SANZ, G. (2007). Enseñar Lengua. Barcelona: Grao.

CORNAIRE, C., \& RAYMOND, P. M. (1999). La production écrite. Paris : CLE-International. De BEAUGRANDE, R. (1984). Text production. Toward a science of composition. New York: Ablex. 
DEWAELE, J.-M., \& WOURM, N. (2002). L'acquisition de la compétence sociopragmatique en langue étrangère. Revue française de linguistique appliquée, VII(2), 139-153.

DÍAZ, J. (2011). Evolución del Francés Lengua Extranjera en España. CEE Participación Educativa, 16, 122-132.

DIDACTEXT. (2006). Secuencia didáctica para la escritura de textos expositivos. En Textos de didática de la lengua y la literatura (p. 97-106). Barcelona : Graó.

FAYOL, M. (1991). From Sentence Production to Text Production: Investigating Fundamental Processes. European Journal of Psychology of Education, 6(2), 101-119.

FLOWER, L. (1985). Problem - solving etrategies in writing (Segunda ed.). New York: Harcourt Brace Jovanovich.

GALBRAITH, D. (2009). Cognitive Models of Writing. Gfl-journal, 2-3, 6-22.

GAONAC'H, D., \& LARIGAUDERIE, P. (2000). Mémoire et fonctionnement cognitif: la mémoire de travail. Paris : Armand Colin (collection U).

HAYES, J. (1996). A new framework for understanding cognition and affect in writing. In C. Levy, \& S. Ransdell (Edits.), The science of writing: theories, methods, individual differences (p. 1-27). New Yersey: Lawrence Erlbaum Associates.

HAYES, J., \& FLOWER, L. (1980). Identifying the organization of writing processes. In L. Gregg, \& E. Steinberg (Edits.), Cognitive Processes in Writing. Hillsdale, N.J.: Lawrence Erlbaum.

HAYES, J., \& FLOWER, L. (1986). Writing research and the writer. American Psychologist(41), 1106-1113.

MARTÍNEZ, M., \& ZABALA, C. (2015). Enseñando y aprendiendo a escribir en la universidad: cuando los revisores son los compañeros. REDU Revista de la Docencia Universitaria, 13(3), 105-124.

MORA MONCADA, A. Y., \& MURCIA OLAYA, I. D. (2009). Relación entre las estrategias de aprendizaje de los estudiantes de francés de licenciatura en educación básica con énfasis en bumanidades e idiomas de la Universidad libre de Colombia y su nivel de competencia comunicativa. Bogotá: Universidad Libre de Colombia.

RAAIJMAKERS, J., \& SHIFFRIN, R. (1981). Search of associative memory. Psychological Review, 88, 93-134.

ROHMAN, D., \& WLECKE, A. (1964). Pre-writing. The construction and aplication of models for concept formation in writing. Office of Education. Cooperative Research Project, 2.174. 
SALAZAR SIERRA, A. M. (2007). Escritura, Pedagogía y Universidad. Hacia un modelo de escritura óptima. Bogotá : Pontificia Universidad Javeriana.

SCARDAMALIA, M., \& BEREITER, C. (1992). Dos modelos explicativos de los procesos de composición escrita. Infancia y aprendizaje, 43-64.

SHIH, M. (1986). Content based approaches to teaching academicwriting. TESOL Quarterly, 20(4), 617-648.

TORRANCE, E. P. (1998). Torrance Tests of Creative Thinking: Norms Technical Manual Figural (Streamlined) Forms A \& B. Bensenville, Ill: Scholastic Testing Service.

VALETOPOULOS, F. \& LAMPROU, E. (2008). Evaluation des besoins langagiers des apprenants chypriotes hellénophones en français à partir d'un corpus d'écrits d'apprenants. In J. Burston, M. Burston, E. Gabriel \& P. Pavlou (Edits.), Languages for Intercultural Dialogue (128-138). Nicosia: The European Parliament Office in Cyprus and the Ministry of Education and Culture of the Republic of Cyprus.

VILLARREAL CORRECHA, E. (2009). Le plurilinguisme: une nouvelle perspective pour le francais en Colombie. Bogotá : Pontificia Universidad Javeriana.

VILLARREAL CORRECHA, E. (2009). L'analyse de la compétence écrite: le cas de la dissertation. Université de Poitiers (2016), 59, 306.

Van DIJK, T., \& KINTSCH, W. (1983). Strategies of Discourse Comprehension. New York : Academic Press.

ZETILI, A. (2010). Quelles pratiques de classe pour enseigner la production écrite ? Synergies Algérie, 9, 159-172.

Recebido: 17/02/2017

Aceito: 06/08/2017 